\title{
TOWARDS A “LITERARY” TRANSLATION OF THE SCRIPTURES: WITH SPECIAL REFERENCE TO A "POETIC" RENDITION
}

\author{
E.R. Wendland ${ }^{1}$
}

\begin{abstract}
This study proposes a more dynamic, or "mediated," approach to Bible translation as one possible option (among many), should this be called for by the contextual circumstances of the target language setting. Such a method features a genre-based, functional application of interlingual discourse analysis and representation that aims to reproduce the literary (especially the "poetic") quality and energy of the original text (certain aspects of its structure, style, impact, and appeal) within a new linguistic and sociocultural environment. The importance of this local milieu requires the active participation of the target language community during the formulation and execution of an appropriate translation brief, or planning document, including the project's principal communicative purpose (skopos). Another important variable to be examined is the primary channel of textual representation. Here, the oral-aural mode is emphasised due to its particular relevance in Africa. My presentation concludes with an overview of some of the critical cost-versus-gain factors that need to be considered when planning for the production of a literary version.

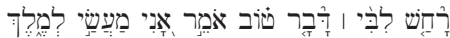

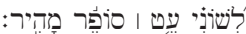

Beautiful words stir in my mind, as I compose a piece for the king.

Like the pen of a skillful scribe, my tongue is ready with a poem.

(Psalm 45:1; Heb. v. 2 - GNB, modified)
\end{abstract}

\section{OVERVIEW}

How often do expressions like those of the preceding passage fill the minds of those who are charged with the responsibility of rendering these words in another language? Does the notion of "beauty" ever come into serious consideration? In this article I wish to take up the challenge of the psalmist - actually, to pass it along to those translators who happen to be in a position possibly to carry it out. The issue here concerns a special type of translation, namely, one that seeks to duplicate the literary artistry and rhetoric

1 Dr. E.R. Wendland, Centre for Bible Translation in Africa, University of Stellenbosch/United Bible Societies. 
of the source language (SL) text by an communicatively equivalent text in the target language (TL) - in short, to render literature as literature, or in this case, poetry as poetry. ${ }^{2}$ There may be many reasons not to attempt such a "literary translation," some of which will be alluded to in this study. However, both the content of the verse above (꼬ำ "good news") as well as

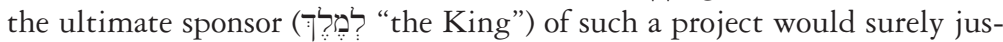
tify the effort and expense that is ultimately required.

I will develop this inquiry by exploring several of the key terms (along with associated concepts) that are found in my title: What do we mean by "literary", "translation", and "a poetic rendition"? In what respects are the Scriptures "literature"? This exercise is rather more complicated and controversial than it may at first appear because the respective definitions are in each case roundly debated by biblical scholars and literary critics alike. The crucial oral-aural channel of message transmission also needs to be considered in the planning process. The preceding key factors lay the foundation then for my argument that a literary translation is not only possible, but it is also highly recommended - if the relevant circumstances allow. What are these conditions, who determines whether or not they apply to the case at hand, and how are they best evaluated in relation to a given translation endeavour? I will conclude with several considerations that may assist project planners to evaluate the major pros and cons of a literary type of version in relation to the particular TL community envisaged.

\section{WHAT IS “LITERATURE”?}

The adoption of a literary approach during text analysis and translation presupposes that the Bible is in fact "literature" - that the various books which it includes, whether as wholes or in part, are generally regarded as being "literary" in character and consequence. This matter will be discussed more fully below (Section 4.1). But what precisely do these commonly used terms mean to most Bible interpreters and translators? Many people assume that they know what is being referred to simply because they have heard the words so often. But if you ask them to define "literature," for example, it quickly becomes obvious that familiarity does not necessarily mean understanding. This is really not surprising since even the experts do not always agree. The issue of definition is of considerable importance because it will affect both what one looks for in the original text(s) of the Scriptures

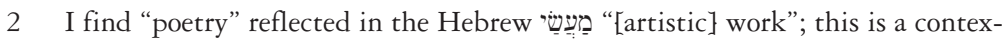
tual construal, but a defensible one since this term stands in close proximity

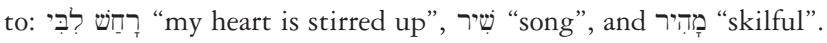


and also how one decides to deal with this in any translation where the literary qualities of the language concerned are in immediate focus.

Various designations of literature have been proposed. The following extract from a popular dictionary entry will get us started:

all such writings (in prose or verse) considered as having permanent value, excellence of form, great emotional effect, etc. ... because of their beauty, imagination, etc. (Guralnik 1988:689).

This definition encompasses form, content ("value"), and function ("effect"), for these three interrelated features are the essential diagnostic components of any oral or written verbal message, whether artfully or poorly composed. It is important to note here, however, that not just any sort of text is included within the scope of literature; rather, the crucial exercise of evaluation is inevitably involved. In other words, we are referring to a document that is generally regarded as being "permanent", "excellent", even "great" with regard to "beauty", "imagination", and presumably also subject matter, impact, appeal, and relevance. Although such a qualitative assessment may be made simply by popular acclaim, this activity is usually carried out and substantiated by recognised literary experts, scholars, critics, and actual artists. This fact needs to be kept in mind then in cases where a specifically literary version of the Bible is being translated: who will be doing the evaluation and how, that is, according to what criteria or standards of excellence?

To be more precise then, what constitutes "literature" for any translation project that aims to emulate it will depend on its predetermined organisational skopos (see Section 3.3). Generally speaking, however, two broad perspectives on the subject can be adopted, as schematised in terms of form, content, and function according to the following figure:

\section{Synchronic}

FORM :

Diachronic development... $\ldots \ldots \ldots \ldots \ldots \ldots \ldots \ldots \ldots \ldots \ldots \ldots \ldots$

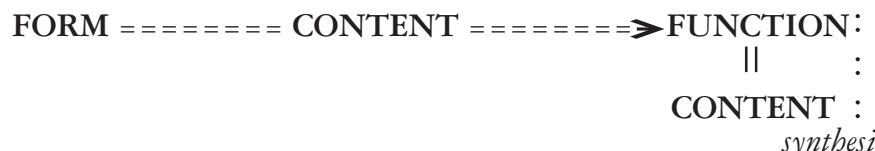

synthesis

Figure 1: Two perspectives in the evaluation of "literature" 


\subsection{A "popular" (social) perspective}

"Of course it's a work of art. It's in an art gallery."

Due to the influence of some sort of anachronistic ageing process, an earlier, mediocre piece of writing in terms of form and/or content may with the passage of time eventually be regarded functionally in a much more positive aesthetic light. This sort of favourable characterisation, whether unsophisticated or scholarly in origin, is usually based on widespread usage, perhaps supported by a particular attraction for a more antiquated literal expression, in accordance with the whims of popular opinion. This is largely an emotive evaluation that is motivated to a large extent by the ritual and performative functions of language, which tend to be activated in or by certain settings of sociocultural, including religious, significance, especially the formal liturgy of public worship. ${ }^{4}$

Nida and Taber point out another aspect of this progressive and cumulative diachronic development:

3 This is how some people judge "literature" too; a certain text qualifies as such if it happens to be found on the same bookshelf with recognised literary works. So what does certify a verbal message as being a literary "work of art"? I will be exploring some possible answers to this important question in the sections that follow. The quote above is attributed to Damien Hirst (May 1994); it is cited in Pilkington (2000:3). For many people of course this whole matter is a non-issue; the Bible is above "literature" (i.e. a buman creation) because it is a divinely inspired religious document.

4 It is possible therefore that an older, literal translation will become popularly regarded as being "literary" in a given language and by a particular constituency as a result of long liturgical usage, which creates an exotic, but valued compositional style within the tradition. More commonly, however, a strictly literal rendering (one that lacks, for example, a euphonous manner of expression, attractive lexical collocations, or any phonological and rhythmic shaping) will turn out to be obviously unnatural according to TL linguistic norms (e.g. NASB). This is not to say that such a version will be rejected by its intended audience group, for the relative acceptability of a given translation is determined by a number of interacting sociolinguistic as well as religious influences. In addition, one must also consider the factor of relative quality; not every so-called "literary version" of the Bible is a good example of this translation type. Take the NEB, for example; while it manifests occasional flashes of stylistic brilliance, these do not occur often or consistently enough and with enough duration for the translation as a whole to be rated very highly. 
In many languages that have been reduced to writing within the last two or three generations there is a kind of 'literary' capstone ... which may be regarded by many literate persons in the language as the only appropriate form to write the language (1969:124).

Thus, not only is a certain period of time generally required for such a favourable professional and/or public assessment to grow with regard to a particular written work, but important, sometimes extremely complex sociolinguistic factors may be involved as well, e.g. extensive publicity, celebrity endorsement, political propaganda, large church sponsorship. However, the actual stylistic qualities of the translation itself are not usually considered in detail, if at all, during this process. Although there are a number of examples of such a popularly defined "literary" translation in the world, also in Africa (e.g. certain long-serving "missionary" versions), this is not what I have in mind in the present study.

\subsection{A "technical" (stylistic) perspective}

A technical definition of literature is usually based upon some type of synchronic study that produces an analytical description and assessment of a given work's harmonious integration of form, content, and function within an appropriate contextual setting. Experts in the field examine the text, whether an original composition or a translation, according to recognised "universal" (or in some cases "regional") literary features — such as elaborately patterned repetition, rich thematic symbolism, novel figurative language, culturally resonant key terms, subtle phonic artistry, or the skilled use of ideophones and expressive exclamations (features of Bantu orality). They proceed to evaluate it with reference to these explicit stylistic criteria along with traditional or locally favoured aesthetic standards, codes of formality, and prevailing social conventions, whether or not the work happens to be widely accepted by the population at large. ${ }^{5}$ This is the general perspective and approach that I have adopted in the following discussion. It

5 Toury stresses the sociocultural aspect of literary evaluation:

Thus, in every culture ... certain features, models, techniques (including modes of translation!) and - by extension - texts utilizing them, are regarded as, rather than are literary in any 'essentialistic' sense. ... [L]iterary translation involves the imposition of 'conformity conditions' beyond the linguistic and/or general-textual ones, namely, to models and norms which are deemed literary at the target end. It thus yields more or less well-formed texts from the point of view of the literary requirements of the recipient culture, at various possible costs in terms of the reconstruction of features of the source text (1995:170-171, original emphasis). 
may be expected then that a literary translation (LT), which has been creatively composed along these lines will also, sooner or later, come to be regarded as such also in a popular, diachronic sense.

Thiselton refers to the "rich reading" that a genuinely literary text encourages due to its "multilayered coding": it is thus "open" or "productive" in terms of form and meaning and therefore either conveys or evokes varied "resonances, intertextual allusions, new perspectives, [and] transformed horizons" (1999:169-171). To a great extent such a stylistically "marked" text and/or a semantically enriched interpretation is promoted by an emphasis upon what Roman Jakobson termed the "poetic function" of language, which activates additional metaphorical and other associative relationships to augment the conceptual density of the discourse. This is effected by "[t] the verbal material [which] displays overall a hierarchical structure of symmetries, based on repetitions, regularities, and systematizations of various kinds" (Pomorska and Rudy 1985:150). The result is a more intricate linguistic network or layering (i.e. than that normally found in "prosaic" texts) of formal parallels and verbal correspondences - contrasts as well as similarities — involving sound, sense, syntax, and text structure. ${ }^{6}$ Such poetic structuration and stylistic embellishment is not gratuitous or selfserving however. In literature of great cultural (including religious) significance, the artistry is always utilised to enhance the impact and appeal of intended message, for example, to highlight or to integrate major thematic motifs and emotive strands.

A comprehensive, complete, and credible analysis of any piece of literature must always precede and form the basis for its recreation in another language. A "literary" examination of this kind may be carried out by means of two distinct, but often related operations, as shown on the following diagram (Fig. 2).

Toury is a prominent representative of the school known as "descriptive translation studies"; they "lay aside prescription" and seek to be "diagnostic rather than hortatory" in their analyses (Hermans 1999:7-9,17,28).

6 On the continuing influence of Jakobson's structuralist-poetic approach to literary analysis, see Green's recent detailed study of the Beatitudes (2001:21). 


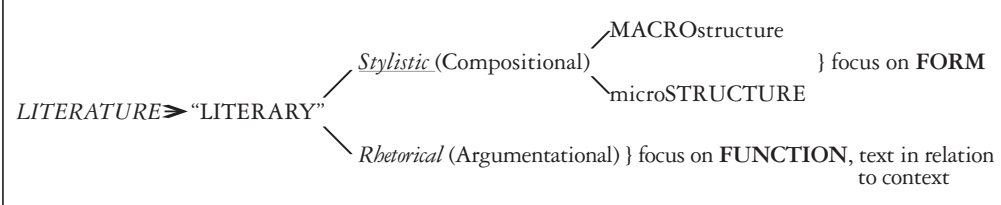

Figure 2: Aspects of "literary" analysis

Assuming then that we are beginning with an acknowledged instance of literature in the SL, it may be analysed with special attention devoted to either its form or its function. In the case of the former, a "stylistic" study, the compositional organisation and aesthetic features of the text are investigated on the macro- and/or the micro-structure of the discourse as a whole, usually in relation to its intended (source) or perceived (target) meaning. A "rhetorical" analysis, on the other hand, focuses upon the argumentational dynamics and affective dimension of the discourse - that is, how the author shaped the text in order to move or persuade his/her intended audience to adopt a certain conclusion, opinion, perspective, conviction, or motivation (purpose) in relation to the message, whether as a whole or concerning selected portions. Both types of literary analysis are required to lay the proper foundation for a rendering of the same overall communicative quality. This process must therefore be repeated also with respect to literature in the $\mathrm{TL}$ - first in general to determine the genre-based inventory and artistic resources that are available to choose from, and then with specific translational application to the text at hand (cf. Section 3).

\subsection{The crucial importance of literary "genre"}

"Genre" may be generally defined as a certain type or class of something, but more specifically as "[a] category of artistic composition [...] marked by a distinctive style, form, or content" (Soukhanov 1996:656). In the present context we are referring to the organisation of verbal art in its diverse manifestations - from prose to poetry. "Form" in this case may be seen as denoting the larger structure and/or the rules of arrangement of a particular discourse or even a corpus of texts. A given genre may be described with reference to different levels of specificity (sub-genres) or to particular sociocultural settings in which certain types of text typically appear or are regularly performed. Two different perspectives may be adopted with respect to the study of genre in a given sociocultural context - that of the foreigner or "universal" observer (i.e. a generalised etic viewpoint) or that of the indi- 
genous insider (a specific emic view). Due to our relative lack of knowledge about the various emic (sub)genres recorded in the Bible and how to define them, I have adopted a largely etic perspective in the following discussion.

An audience (or readership) apprehends a selected discourse in their language, whether oral or written, with an acquired literary (as distinct from linguistic) competence, based on learning and past experience. This enables them to discern and interpret the characteristic stylistic features that are present in specific types of text. The more experienced the readers or listeners, the greater is their active, critical competence. The recognition of genre and various expectations associated with it are a fundamental part of this ability. Genre then refers to a cognitive template, an interpretive framework, that facilitates an audience's processing and evaluation of a text's form (e.g. poetic devices), content, purpose, and significance. Enjoyable or disconcerting surprise may be evoked when a particular genre's norms are deliberately flouted, altered, or ignored.

The diverse codes and verbal conventions associated with different genres "are capable of different kinds of meaning and offer different kinds of information to a reader" (Tate 1991:64). However, such a significant meaning potential exists only in a virtual state until it is actualised by someone who is familiar with the formal system of linguistic and literary signals of the genre and related sub-genres or tropes which have been built into the text by the original author. Robert Alter (1981:46) describes the process thus:

A coherent reading of any art work, whatever the medium, requires some detailed awareness of the grid of conventions upon which, and against which, the individual work operates ... An elaborate set of tacit agreements about the ordering of the art work is at all times the enabling context in which the complex communication of art occurs. Through our awareness of convention we can recognize significant or simply pleasing patterns of repetition, symmetry, contrast; we can discriminate between the verisimilar and the fabulous, pick up directional clues in a narrative work, see what is innovative and what is deliberately traditional at each nexus of the artistic creation.

Knowledge of generic organisation and stylistic operation can lessen the likelihood of one's misinterpreting an artistic piece of literature, for example, one in which the use of metaphor, irony, paradox, or hyperbole is a prominent feature:

The genre provides the literary context for a given sentence [text] and, therefore, partly determines what the sentence [text] means and how it should be taken ... Genre thus enables the reader to interpret meaning and to recognize what kinds of truth claims are being made in and by a text (Vanhoozer 1998:50). 
Ignorance of or disregard for the formal and semantic norms associated with a given genre can lead to what James Barr (1963:125) terms a "literary category mistake":

Failures to comprehend the literary genre lead to a use of the biblical assertions with a wrong function ... Genre mistakes cause the wrong kind of truth values to be attached to biblical sentences. Literary embellishments then come to be regarded as scientifically true assertions.

It is clear, therefore, that special attention devoted to both the generic and the specific literary-rhetorical forms of biblical discourse can direct one more confidently along the path of a meaningful interpretation of such artistically composed theological literature. This is not merely a matter of structural identification, for the conventional form is merely the primary means to a more important end - namely, a better understanding of the author's message in terms of conceptual content and affective intent (function) as well. It is not surprising that an accomplished secular translator and literary critic concludes: " $[\mathrm{R}]$ ecognition of genre and its rules is the translator's most important task" (Katan 1999:150).

Of course, there are different ways of designating and defining certain larger macro-genres — such as, history, prophecy, gospel, epistle — also of subdividing them into more specific categories, e.g. "biography," "diatribe," "midrash," "aphorism," "admonition," "vision/dream," "genealogy," "royal decree." Certain pericopes found within the narrative gospels, for instance, may be analysed as belonging to one or more of the following formfunctional sub-categories: pronouncement stories (of correction, commendation, objection, quest, inquiry); parables; wonder accounts (of exorcism, healing, provision, controversy, rescue, epiphany); promise and commission epiphanies; genealogy, hymn, prayer, apocalypse, liturgy. The New Testament epistles are frequently elucidated with reference to the specific literaryrhetorical forms (types and patterns) that hark back to the categories of ancient Greco-Roman oratory and letter-writing, e.g. the sequential stages of an argument, diatribe, exhortation, encomium, topoi, virtue-vice lists, the household code, liturgical fragments, salutation-blessing-doxology, travelogue (Bailey \& Van der Broek 1992:21-86).

The value of these diverse systems of literary classification lies not in their intrinsic worth, that is, in their static use as a means of precise formal identification (e.g., "utterance X is an aphorism"). It is seen rather in their dynamic textual application to more adequately reveal the varied compositional organisation, thematic movement, and communicative purpose of a given pericope. Knowing the standard form is also helpful in determining 
where and why an author modifies an expected conventional pattern in order to achieve some special emotive effect - audience criticism, for example, as when Isaiah transforms an apparent love song into an oracle of divine judgement (Isa. 5:1-6), or when Paul pointedly omits the opening "thanksgiving-and-prayer" section in his letter to the Galatians (Gal. 1:6ff). Similar rhetorical results may — or should — accordingly be sought in the language of translation, certainly one that aims to be somehow "literary" in nature.

\subsection{The prose $\Longleftrightarrow$ poetry continuum}

As described above, etic genres, like individual texts, may be classified and described with respect to different levels of generality. Most analysts distinguish two basic macro-genres, prose and poetry. In some literary traditions, the difference between these two types is relatively clear-cut and easily specified. This normally occurs in cases where the various kinds of poetry are strictly defined in terms of fixed linguistic/literary categories - most commonly, some combination of the following features: meter, rhyme, line length (syllable count), versification (balanced lines, strophes, stanzas), which are then designated by particular technical terms (e.g. "sonnet", "choric ode", "epic"). However, in the case of other, perhaps most, world literatures, including Biblical Hebrew, the distinction between prose and poetry is quite a bit more flexible and depends more on a particular concentration or combination of what may be termed conventional "poetic", as opposed to more "prosaic" stylistic features.

Poetry characteristically foregrounds the phonic, or auditory, as well as the imagistic, or visual, potential and dimension of a given language. In the Hebrew corpus of relatively more poetic discourse would be found a greater incidence of devices such as: parallelism; figurative language (especially metaphor/simile) and symbolism; word order variations (item advancement or retrogression); word-plays (punning); sound-plays (alliteration, assonance); condensation (e.g. frequent ellipsis, including the waw "and" in the second line of a couplet); patterned reiteration (both contiguous and displaced); exclamation; intensification (including hyperbole); rhetorical/deliberative questions; the vocabulary of worship (prayer, praise); direct speech (with vocatives, imperatives, idioms); and various degrees of significant allusion (intertextual as well as extratextual). In addition to a higher fre- 
quency, density, and intensity of usage with respect to these characteristics, ${ }^{7}$ Hebrew poetry is also distinguished by a significantly reduced occurrence of the so-called "prose particles": the sign of the direct object ('th), the definite article $(b-)$, the relative clause marker ('shr), and the inseparable prepositions (m-, l-, $\left.k_{-}, b_{-}\right)$.

A given literary text may be classified or interpreted as being more or less poetic on the basis of the relative quantity of such features present as well as their distribution in the discourse. Some indeterminacy and hence controversy occurs, for example, in a number of OT prophetic and wisdom texts (e.g. Jeremiah, Ecclesiastes) and also in certain NT epistolary passages (e.g. 1 Cor. 13, Phil. 2:6-11, Col. 1:15-20), including those that quote LXX poetry, such as Hebrews (e.g. 1:5-13). Even in passages that are predominantly narrative in nature, distinctive poetic "inserts" occur for the purposes of foregrounding: for example, in many of the crucial speeches of Genesis (e.g. $1: 26 ; 2: 23 ; 3: 14-19 ; 4: 23 ; 8: 22 ; 9: 25-26 ; 12: 2-3$ ) or the biblical citations of Matthew (Green 2001:chs. 3-4). Here once again, it is not so much the form or classification that is important for interpreters, but rather the function, especially where the poetically heightened style of discourse is being utilised to enhance or to emphasise a particular portion of the text (e.g. the central theological subject/theme of the three epistles mentioned above). On the generic level too we find a certain amount of functional overlapping, with some instances of the same macro-genre being manifested in more or less poetic $\Longleftrightarrow$ prosaic terms, depending on the text being examined, for example: paraenetic (Amos $3>$ [more poetic than] Galatians 3), didactic (Job $20>$ John 3:1-21), descriptive (Song of Songs $4>$ Revelation 1:12-16), apocalyptic (Ezekiel 38-39 > Matthew 24).

The variable prose-poetry continuum is also illustrated in texts where the principal genres are combined. For example, prophetic hortatory discourse, or "oracular prose", which occupies such a prominent place in the Hebrew Scriptures, incorporates most of the Hebrew poetic types, along with various more "prosaic," including narrative, portions of discourse.

7 Adele Berlin regards the "elevated style" of Hebrew poetry to be "largely the product of two elements: terseness and parallelism" (1985:5). It is not really possible to strictly define "poetry" per se, only to characterise it with regard to a particular literary tradition in terms of a set of distinctive, relatively more "poetic" (versus "prosaic") features. Accordingly,

[p]oetry takes full advantage of and concentrates the resources of a language [i.e., in terms of frequency, predominance, density, intensity] and [thereby] widens its [semantic] possibilities ... (Schoekel 1988:19). 
These texts may be divided into "reports", "prayers", and the largest category, "speeches" (Westermann 1967:90-92). "Didactic" and "apocalyptic" types of poetry are similarly classified, but not usually in as much detail. In the New Testament prose is clearly predominant, but important (though debatable) instances of poetry, or "poetic prose", also occur, as noted above. In any case, the important consideration is not the form of these poetic segments, but their primary communicative, specifically rhetorical, purpose within the discourse as a whole.

Of course, much finer generic prose-poetry distinctions than the preceding can — and perhaps must — be made, depending on the indigenous literary categories into which a given text of Scripture is being transplanted. But the preceding observations may be sufficient to guide translators along the path of initially differentiating the many types of biblical literature that they will encounter in terms of form, content, and function. This will better prepare them to find correspondences in their own language and literature in a reverse order of priority/significance, that is, from the greatest to the least: function $>>$ content $>>$ form. Thus a comparative functional analysis may indicate that a poetic, accusatory prophecy such as Obadiah may be more effectively rendered as emotively heightened prose in a given target language - or vice-versa, for example, the genealogy of Genesis 5 recast in the distinctive form of Bantu "praise poetry." A functional focus in the study of genre is well complemented by a speech act approach to the analysis of texts and text constituents, especially where direct discourse is involved, which is the preferred, dramatic mode of biblical composition.

An awareness of these structural categories along with their associated stylistic characteristics enables the literary analyst to carry out discourse studies that are more discerning, precise, and stimulating with reference to both form and function. However, taken to an extreme, such attempts at description and classification tend to become highly subjective and overly complicated, thus confusing rather than clarifying the text at hand. Similarly, the search for possible literary, or "genuine" poetic, equivalents in a given target language may easily be taken too far. The result then is a translation that is formally unnatural, functionally inappropriate, or worse - completely incoherent due to serious collocational clashes in terms of genre and style. A more effective strategy would be to train verbally-gifted translators to accurately recognise and evaluate such features comparatively in both the SL and the TL, then simply allow them the freedom to creatively transform 
the biblical text into their mother tongue by the holistic, synthetic process of artistic ("inspired") intuition. ${ }^{8}$

\section{WHAT IS “TRANSLATION”?}

Thus far we have delineated the nature of the object of our concern namely, the "literature" of the biblical text - as well as the objective of this endeavour, that is, to produce a recognised "literary" textual equivalent in some contemporary world language. Now how do we get from A to B, from SL to TL? Obviously, some type of "transformation-and-transfer" process is necessary: the message originally conceived by a biblical author must be conceptually transported, as it were, across the boundaries or barriers of time, space, language, thought, and culture, then verbally reconstituted within a very different situational setting. How is this process to be carried out in the most reliable (accurate) and relevant (efficient and effective) way possible?

\subsection{Translation as a complex, "mediated" act of communication}

Translation is a very specialised, complex, and manifold type of verbal communication - an interpersonal "sharing" of the same text (an integrated, meaningful systems of signs) within two different systems of language, thought, and culture. In other words, translation involves the re-signification and re-conceptualisation of one text in another linguistic and sociocultural setting. ${ }^{9}$ This multilingual, intersemiotic, cross-cultural process of textual representation and cognitive reference may be variously defined and described in greater or lesser detail, depending on a number of important factors, for example: the underlying theoretical model that one adopts; the designated purpose, or skopos, of the translation in relation to the target audience; and the style or manner in which the re-composition is carried out (e.g. relatively literal versus idiomatic in nature). I suggest the following componen-

8 Such a more intuitional, instinctive ("inspired") method of translation — carried out by an expert practitioner of course - appears to be similar to that proposed by the French "interpretative" school of theorists (i.e. ESIT, as described in Sterk 2001).

9 A translation of the "holy" Scriptures imposes a greater constraint, obligation, and/or responsibility upon translators to preserve the "meaning" (however defined, i.e. +/- SL forms) of the original text due to its perceived divinely generated, hence determinative and authoritative, nature for a particular religious community as well as for individual users. 
tialised definition of the process of literary translation (in italics on the left side of Fig. 3 below; the material in brackets on the right is explanatory):

LITERARY TRANSLATION

\begin{tabular}{|c|c|}
\hline a) involves the mediated re-composition & $\begin{array}{l}\text { [the translator acting as a conceptual "bridge" } \\
\text { between two texts and contexts] }\end{array}$ \\
\hline b) of one contextually-framed text & $\begin{array}{l}\text { [linguistically, socioculturally, institutionally, } \\
\text { and situationally context-sensitive] }\end{array}$ \\
\hline c) within a different setting of communication & $\begin{array}{l}\text { [the "negotiated sharing" of a verbal message } \\
\text { in a new language }+ \text { mind-set] }\end{array}$ \\
\hline d) in the most relevant, *...* manner possible & $\begin{array}{r}\text { [the most cognitive-emotive-volitional effects } \\
\text { vis-à-vis the least processing effort] }\end{array}$ \\
\hline e) * functionally equivalent $*$ & $\begin{array}{l}\text { Lan acceptable, appropriate, appreciable degree } \\
\text { of "similarity" in terms of the ... }\end{array}$ \\
\hline f) & $\begin{array}{l}\text { "meaning" variables of pragmatic intent, } \\
\text { semantic content, and textual-stylistic form] }\end{array}$ \\
\hline g) in keeping with the overall brief & $\begin{array}{l}\text { [specific aims/skopos, available resources, tar- } \\
\text { get-audience, medium, etc.] }\end{array}$ \\
\hline h) of the TL project concerned. & $\begin{array}{l}\text { [the overall communicative "frame-work" of } \\
\text { the TL setting is determinative] }\end{array}$ \\
\hline
\end{tabular}

Figure 3: A factored definition of "literary translation"

I will briefly comment upon the explanatory material in brackets above as it relates to this particular definition. To begin with, it is important to note that translation is different from monolingual communication in that at least two different external settings and interpersonal situations are involved, and often a third, if the translators cannot access the original text directly (cf. [c] on Fig. 3). The formal and conceptual "distance" between these two (or three) contexts is variable, depending on the languages and cultures concerned. Generally speaking, the greater this distance, the more difficult the translation task and more proactive "mediation" on the part of the translator is required (a) — that is, if a meaning-oriented version is being prepared. ${ }^{10}$

10 A more SL form-oriented, "foreignised," translation of the Scriptures may be desired for various reasons, depending on the specific communicative situation (e.g. to facilitate the tradition-based ritual function of communication or to expand the literary categories/features of the TL) and/or the interpersonal setting concerned (e.g. the formal similarity of the translation to some familiar existing version in the TL or another, accessible language). The focal text of my study also emphasises form, namely, the literary forms of the TL that are resourced and capitalised upon during the production of a "poetic" rendering. The degree of textual "domestication" is therefore quite considerable, but so are the poten- 
Each of the distinct communication settings incorporates several interacting "levels" or dimensions of extratextual influence that together affect all aspects of text representation - its production, transmission, and processing (b). There are thus cultural, institutional, religious, physical (environmental), interpersonal (sociolinguistic), and personal (psychological, experiential) factors that pertain to the communication context. These all merge to form the respective collective "cognitive frameworks" of the source language or target language communities (and the individuals of which they are composed).

The current, audience perspective and opinion then is determinative (h) during the formal drawing up of an organisational brief that defines the overall purpose (skopos), principles, and procedures of a given Bible translation project for a particular target group and communication setting $(\mathrm{g}) .^{11}$ In terms of my definition, translating with a specifically "literary" version in mind is carried out according to the general principle of "relevance" (d), coupled with the skopos-specific practice of "functional equivalence" (e), which is applied with respect to textual form, content, and intent (f). ${ }^{12}$ Another type of translation — for example, a more literal version for liturgical purposes - may be defined just as above, except for excluding the qualifier of "relevant" (i.e. "functional equivalence": *e-f*).

Hatim and Mason (H\&M) have some pertinent things to say about the difficulties that translators face when dealing with texts that are stylistically more "dynamic" (or "turbulent") in nature, like the poetic version that is the focus of this study. Such an oral or written discourse consists of a higher incidence of novel or unpredictable, rhetorically "marked" forms and "the

tial positive "contextual effects" that an artistically aware and appreciative audience may derive from such an idiomatic manner of expressing the Word of God in their mother tongue.

11 I use the terms "brief" and "skopos" more or less as defined according to functionalist Skopostheorie (cf. Nord 1997:137, 140, ch. 3; Fawcett 1997:ch. 9; also 2.3 below).

12 For a handy survey of "relevance theory" (RT) as applied to Bible translation, see Gutt (1991; 1992); the theory of "functional equivalence" (FE) is described and applied in De Waard and Nida (1986). I view RT as being a useful way of conceptualising the process of communication in general, but inadequate (rather too abstract, esoteric, and subjectively-applied) when it comes to teaching mother-tongue translators the basic principles and specific procedures of Bible translation. For the latter, an FE approach, or some recent modification of this (cf. Wilt 2002), is much more helpful in practical pedagogical terms (cf. also Nord 1997; Hatim \& Mason 1997:ch. 11). 
use of language that essentially involves a motivated deviation from some norm" (1997:216). That is of course the essence of "artistic" as well as "argumentative" (or "evaluative") composition, two intentions that are often combined in serious ideological "literature" (1997:181-183), which is what the Scriptures embody. This sort of discourse contrasts with that which is mainly "expository" in nature. The latter is characterised by a style that is less marked and more stable, usual, or expected in terms of the language which is used. H\&M offer the following rule of thumb that summarises the translational implications of this relative linguistic-literary polarity:

The less evaluative the text is, the less need there will be for its structure to be modified in translation. Conversely, the more evaluative the text is, the more scope there may be for modification (1990:187).

To elaborate somewhat:

Thus, while an approach which tends towards the "literal" is likely to be appropriate and indeed sufficient for straightforward expository forms of texts (such as news reports — L L I might add simple narrative]), greater latitude may be needed in handling argumentation [or dramatic narrative] effectively. [In other words], ... where the text displays considerable degrees of dynamism, the translator is faced with more interesting challenges and literal translation may no longer be an option (1997:181-182, 30-31).

In fact, I would remove the preceding qualification: when preparing a correspondingly "dynamic" (rhetorical) and/or an "attractive" (artistic) rendition of a literary text, a strictly literal approach cannot be an option. The compositional procedure must be suitably loosened up in order to allow gifted translators the freedom to more fully access and creatively utilise the stylistic and expressive resources of the TL.

Now if one takes into consideration also the unavoidable, all-pervasive contextual factor of culture, the following principle applies:

The less culture-bound a text is, the less need there will be for its structure to be modified. Conversely, the more culture-bound a text is, the more scope there may be for modification (H\&M 1990:188).

What more "culture-bound" discourse could there be than a spiritual song - especially one like Psalm 1 that doubles as an expression of godly instruction (or Psalm 23, as a personal prayer)? Obviously, a considerable amount of formally innovative, but semantically controlled "modification" needs to be made in order to duplicate in another linguistic and ethnic setting the artistic beauty and rhetorical impact of the Hebrew text — yet at 
the same time preserving also the essential theological message of the original author.

\subsection{A "continuum" of translation types}

Obviously, there is not just one way of "doing" a translation. Different types, or styles, of translation are frequently classified on the basis of how closely or loosely they retain the formal features of the source language text in the target language - that is, how "literal" or "idiomatic" they are in linguistic-stylistic terms. An idiomatic version usually has the primary aim of reproducing as much as possible of the semantic "content" of the original message in the TL. Recent secular and Bible-related theory has pointed out that there is another, perhaps even more important factor that needs to be seriously considered in any translation, namely, the intended communication "functions" of the various form-content units that are represented in the SL text. Such a functional approach also applies to the translation as a whole, that is, its intended purpose or prospective use within the TL community. This larger aim needs to be specified and guided by two distinct and not always congruent perspectives, namely, that of the producer(s) of the translation and also that of the designated consumers.

No single translation can reproduce all three elements - form, content, and function - of the original document. ${ }^{13}$ There is rather a variable continuиm of possibilities in terms of selection, focus, and emphasis, ranging from versions that concentrate on the SL forms to those that seek to duplicate the principal communication (text-act) functions of the base document, but using forms that are natural and appropriate in the TL. This hypothetical continuum might be represented as follows (Fig. 4), with a number of English versions cited as possible examples of each type-stage along the way. The diagram also indicates the relative degree of "mediation," or linguistic intervention in the form of TL textual adjustment, that is required to produce a particular translation style. This is not intended to be a qualitative depiction (i.e. type A is "better" than B), but merely a rough reflection of the quantitative "amount" of translational modification involved.

13 The SL message cannot be "reproduced" exactly or completely "conveyed" in a given TL because there will always be an appreciable loss or gain of semantic and pragmatic significance that occurs in the process of interlingual representation. Translators must therefore be selective, aiming to achieve the highest possible degree of "parity," or similarity. But this can be done only with respect to certain aspects of the initial communication event or smaller portions of the SL text - whether the focus pertains to form, content, or function. 


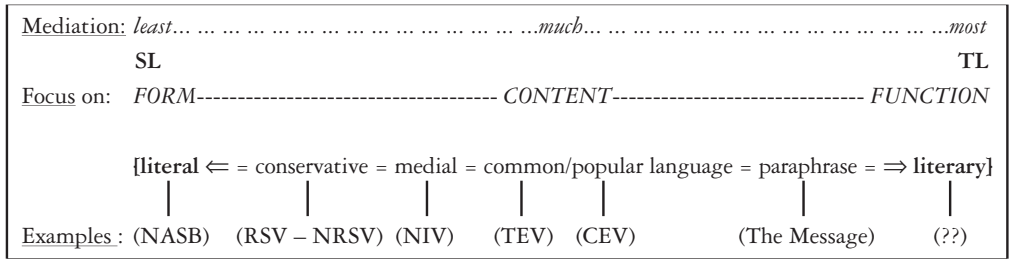

Figure 4: A continuum of common translation types

I do not know of a single, completely "literary" translation of the entire Scriptures composed in contemporary English. ${ }^{14}$ Such an "ideal" version, whatever the language, would be one that generally succeeds in proximately matching (relatively so) the sequence of changing major and minor communicative (e.g. speech-act) functions of the biblical text by the use of suitable micro- (stylistic) and macro-forms (genres) in the target language (TL). Thus a literary rendering also stresses the importance of verbal form; however, it is not SL form, but TL form that is primary. This difference is considerable, but it is not always fully appreciated or acted upon. Therefore, certain translations officially designated or popularly regarded as being "literary" in actual fact may not be so (e.g. NEB, JB) - not formally that is, determined on the basis of recognised secular criteria of excellence with respect to a wide range of phonological, lexical, syntactic, and textual features of artistry and rhetoric in the TL. Furthermore, it is clear that such a critical evaluation would have to be supported by practised literary experts or experienced artists - not merely pronounced by eminent theologians, biblical scholars, or even a multitude of pious proponents of a familiar version revered by a certain religious denomination.

14 That is, literary in a "technical," structural-stylistic sense (cf. Section 2.2). This rather negative conclusion is partially supported by the detailed, but selectively limited, study of Norton (2000). I would grant that other translation types, including a "literal" version (if composed by a master wordsmith), might also manifest certain artistically marked or "literary" features from a TL perspective. However, such qualities would normally not be realised to the same degree on all levels of linguistic structure (for a recent new attempt, see Alter 1996). On Fig. 4, a "literary" (that is, a completely "trans-formed") version is viewed as being more functionally oriented than a "paraphrase" due to its emphasis on genre-equivalence in the TL and the desire to achieve a correspondence with regard to artistic, as well as rhetorical, attributes — while at the same time maintaining an essential semantic equivalence with the original text. 
The easiest way for the preceding form-functional criterion to be satisfied is by means of an "holistic", genre-for-genre rendition of a complete book, text, or pericope - that is, moving from a specific biblical text-type (e.g. a lament psalm) into the nearest functionally equivalent vernacular genre (e.g. Chichewa ndakatulo lyric poetry, cf. Wendland 1993:Ch. 3). It is possible then for the stylistic and rhetorical quality of a literary translation to be effected (composed), perceived, and assessed as a whole according to the objective as well as subjective criteria that have been established for that particular TL genre. ${ }^{15}$ Such a unified creative-compositional approach would seek to attain communicative correspondence (or sufficient "similarity") at a much higher discourse level, rather than in terms of an attempt to match form-functional features on a one-to-one basis with regard to the micro-text.

How much literary "style" or "rhetoric" then can or should be reflected in a given translation, and what are the determining factors involved? In addition, what are the principal hermeneutical implications of this decision? According to an approach that aims for a significant level of "functional parity," the answer would first of all depend on the nature of the SL text being rendered: Thus, the more persuasive and vigorous the rhetoric that is explicitly displayed in the original message (i.e. with special emphasis on the expressive and affective functions of communication), the more "argumentative" or "evaluative" the corresponding discourse ought to sound in the TL. ${ }^{16}$

15 The exegetical quality of the translation in question would have to be evaluated independently according to more semantically oriented analytical methods. It should be noted that I am using the term "literary" here in a broad sense to cover both oral and written texts of a distinctly artistic character, coupled also with a definite rhetorical motivation (cf. Section 4.2 below).

16 These terms are from Hatim \& Mason (1997:182-183), who also point out that such texts tend to be characterised by a higher incidence of "marked" linguistic forms, that is, usages and expressions that are less expected or somehow extra-ordinary in terms of frequency, distribution, or collocation. I have used the word "sound" in this sentence deliberately: The techniques of rhetoric are most obvious and effective when the discourse is either oral to begin with or composed to be presented orally (as in the case of most biblical texts). Rhetoric simply does not carry the same impact when it is read silently to one's self or when composed in the idioms of the SL text (as in Fox 1995). In any case, as already suggested, the relative value of a recent translation may be assessed from two different viewpoints - that of the person or team who prepared it (for whom the minimum standard is "adequacy") and that of the community who will use it (i.e. "acceptability”; cf. Hermans 1999:76, 162). 
Second, the measure of rhetoric that is manifested in a certain translation depends very much on the manner of text representation that was used to prepare it. Simply put: the more literal the type of rendering, the less "rhetorical" the TL version will normally be in terms of persuasive impact and/or aesthetic appeal. The less literal in style - that is, the more idiomatic and literarily accommodative the translation approach that is practised - the more rhetorical the TL text should turn out to be in terms of TL artistic norms and conventions, all other things being equal (e.g. given the same skill and experience of the translators). It also follows that a greater amount of mediation, or creative hermeneutical and compositional "action", is generally required on the part of its translators. In other words, it is necessary for them first to carefully analyse the SL document so that they can understand and interpret its rhetorical processes as well as its primary content (themes, sub-themes, key concepts, etc.). As many as possible of these essential elements of original significance or relevance must then be represented in the translation through the skilful exercise of personal intuitive artistry coupled with a corporate production policy, both textually (in the case of a more dynamic, proactive mode of translation) and extra-textually (through footnotes, introductions, titles, glossary entries, illustrations, etc.).

The preceding considerations will be influenced and modified by another vital aspect of the translation event, that is, the composite human setting of communication. This interpersonal context encompasses the various sociocultural, ecclesiastical, institutional, and individual situations in which the translation will be transmitted, responded to, and utilised. All these factors must be carefully investigated in conjunction with one another before a translation project gets underway because they will, or should, determine the type of version that is most suitable for the target constituency concerned. ${ }^{17}$

\subsection{The importance of a project skopos}

The most important element of the extralinguistic setting of any communication event is of course the intended audience or readership. Past translation theory and practice have usually noted the importance of this human component, but often in unilateral sort of way. That is to say, the act of communication is viewed as a message transmission in one direction, where the author or translator contributes more or less everything, and the audi-

17 I follow Hatim \& Mason is defining "relevance" as communicative efficiency in relation to effectiveness, that is, relative ease of message interpretation in comparison with the degree of accomplishment of its pragmatic goals (1997:12). 
ence simply "receives" the text, interprets it, and then decides how to respond. Recent studies have shown that this is not the case at all - that communication is truly a "shared" process, where an audience brings to a text their own distinct expectations, values, norms, biases, experience, perspectives, and cognitive framework, all of which greatly influence - either to foil or to facilitate - the "message" that they perceive, understand, and ultimately react to.

The hermeneutical significance of audience affect can be taken a step further. Here it concerns the translation project as a whole in that its planners and organisers cannot simply anticipate (or even ignore) their target group. Rather, they must make every effort to find out beforehand the specific nature of their listener- or readership - not only their perceived needs or desires, but their actual, expressed expectations and goals for the translation. In short, representatives of the target constituency must be integrally involved in all aspects of planning for the special type of version that is meant to serve their community within the designated settings where it is intended to be used. This is not to say that the target group determines everything according to their personal "felt" needs, which may in fact be quite removed from an objective assessment of their "real" needs, based on the deeper exigencies and realities of their current and possible future lifesituation. The whole preparatory stage of research and planning must therefore be fully interactive and freely negotiated - that is, a continual dialogue of give-and-take in order to establish the objectives and working document for the entire project. A translation of the "Holy Scriptures" normally calls for a more complex skopos that is both "source-oriented" and "target-oriented" (cf. Hermans 1999:37). From the latter perspective,

[t]ranslation choices normally result from judgements by the translator - or whoever is in a position to control or override the translator - about perceived needs and benefits, audience expectations, personal and collective motivations.

On the other hand, since an authoritative sacred text is being rendered, the translation is viewed

as a vicarious object, a substitute which must constantly be referred back to its source ... [and] checked against the original for faults and shortcomings (Hermans 1999:39-40).

The importance of developing such an explicit operative framework or modus operandi has been greatly stressed in recent translation studies. ${ }^{18}$ The most important component of this overall guiding plan (i.e. the brief) is the

18 Some theorists term this the translation brief, which explicitly sets forth 
particular purpose (or skopos) for which the translation is being made for its primary audience and principal setting of use in keeping with prevailing translational norms in the society concerned. ${ }^{19}$ This official position statement concerning critical objectives and "success factors" is what subsequently determines how the programme will be carried out (its principles and procedures), also when and where this will take place in terms of a schedule and location. It further specifies by whom - with reference to the type of translation staff, both official and auxiliary, who are required to get the job done, including a critical assessment of various drafts, in the most efficient and productive manner. The present article has been written to promote another important compositional option that will hopefully expand the possibilities in this regard. This is a stylistically as well as hermeneutically creative translation that manifests a greater measure of general functional correspondence to both the rhetorical vitality and also the literary beauty of the original text of Scripture.

\section{ASPECTS OF LITERARY TRANSLATION}

In this section I will assimilate the discussion of the first two portions of this paper in order to provide a somewhat fuller elaboration of the nature and purpose of a literary translation (LT; cf. Section 3.1). This is a version that embodies the attempt to textually represent the artistic and rhetorical quality of the biblical text in another language, whether in written, oral, and/or visual form. ${ }^{20}$

information about the intended target-text function(s), the target text addressee(s), the medium over which it will be transmitted, the prospective place and time and, if necessary, motive of production or reception of the text (Nord 1997:137).

19 According to Vermeer (cited in translation by Nord 1997:29):

Each text is produced for a given purpose and should serve this purpose. The skopos rule thus reads as follows: translate/interpret/ speak/write in a way that enables your text/translation to function in the situation in which it is used and with the people who want to use it and precisely in the way they want it to function.

20 This point is discussed in G. Toury 1995:168. Toury also notes the significant ambiguity that is inherent in the designation "literary translation" — that is, literary with reference to the quality of the original text (e.g., the Scriptures) and/or to the particular translation of a given source text, whether the latter happens to be regarded as literary in character or not according to the conventional standards of artistic excellence (1995:168). I am arguing for an application of "literary" to both — to an analysis of the source text (Scripture) and also 


\subsection{Motivation for an LT}

As noted earlier, an increasing number of studies have drawn attention to many significant aspects of the literary character that the Scriptures, at least certain books or pericopes, clearly demonstrate. We find, for example, numerous expertly interwoven genres and literary sub-types; elaborate image sets that are often related in various ways; a great density of figurative, symbolic, and multi-referential language; striking turns of phrase formed by syntactic shifts and ellipsis; many passages that are shaped by sound so as to appeal to the attentive ear; a preference for audience-engaging direct speech; and extensive allusions to and developments of earlier biblical texts. Finally, the Bible frequently manifests emotive, highly evocative discourse, coupled with a forceful rhetorical mode of challenging, even provoking readers and hearers alike with a vital promissory, life-death moral and theological message of utmost relevance both in the here-and-now and beyond the grave. ${ }^{21}$ In short, many detailed stylistic and structural analyses in recent years have convinced a majority of scholars that instances of excellent literature in the Scriptures, the prosaic as well as the poetic passages, are the rule rather than isolated exceptions. ${ }^{22}$

Thus, whether the language is Hebrew or Greek, the diverse texts of the Bible over and above their obvious religious and moral content appear to evince a level of compositional excellence that is outstanding with regard to both the macrostructure and also the microstructure of discourse organisation. Such high quality is clearly manifested in more texts than most people realise, from the skilful selection and combination of complete literary types and genres to the corresponding usage of figurative language, varied grammatical arrangements, subtly interwoven patterns of repetition, rhetorical features such as irony and hyperbole, vivid contrasts, ubiquitous intertextuality, and manifold phonaesthetic combinations. This claim may be supported whether one analyses the discourse from a Semitic, a rabbinic, or

to its reproduction in a given target language. This is the express aim of Alter (1996) and Fox (1995; see the respective prefaces to their translations), though their focus is more firmly fixed upon the formal literary-rhetorical features of the Hebrew text and how these may be successfully reproduced in a given TL, namely, English.

21 Thiselton cogently argues for the prominence of the speech act of promising in biblical writings (1999:231-239), for example: " $[P]$ romise provides a paradigm case of how language can transform the world of reality" (1999:238, author's italics).

22 For several samples of such recent studies, see Breck 1994; Dorsey 1999; Harvey 1998. 
a Greco-Roman stylistic perspective (or all three literary influences in the case of many New Testamemt texts).

Since many passages of the Bible arguably do demonstrate, by and large, a high literary standard, ${ }^{23}$ they implicitly call for a correspondingly high quality of translation to maintain a relative balance in terms of "functional equivalence", communicative "effectiveness", "relevant similarity" (Chesterman 1997:69), or more specifically "aesthetic parity." ${ }^{44}$ In other words, it behoves literary translators to at least attempt to approximate or match this overall level of stylistic excellence and rhetorical effect in the TL text, ${ }^{25}$ to the extent that this is possible - that is, given their particular level of education, competence, experience, and commitment as well as the encouragement and support provided by their translation administrative committee and the community at large. To do any less would represent a conside-

23 I discuss this issue further in "A literary approach to Biblical text analysis and translation" (in Wendland 2002). Several recent extensive studies support this conclusion, for example, with reference to the Old Testament, see Dorsey 1999; for the New Testament, see Davis 1999.

24 With regard to the translational goal of "functional equivalence," De Waard and Nida state:

The translator must seek to employ a functionally equivalent set of forms which in so far as possible will match the meaning of the original source-language text (1986:36).

"Meaning," in turn, is not only "informative" in function; it is also "expressive" and "affective" in nature. Concerning the issue of a translation's quality, Hatim and Mason propose that

one might define the task of the translator as a communicator as being one of seeking to maintain coberence by striking the appropriate balance between what is effective (will achieve its communicative goal) and what is efficient (will prove least taxing on users' cognitive resources) in a particular environment, for a particular purpose and for particular receivers (1997:12; original emphasis).

However, the matter of the translator's responsibility is also relevant here, that is, with respect to the communicative intentions and literary quality of the original SL text.

25 According to Pilkington (2000:160, 161)

any account of poetic effect or literariness must include an account of affective communication. ... The point of poetic effects and literariness more generally ... is to broaden context, and make both thoughts and feelings richer, more complex and more precise with regard to actual situations or states of affairs. 
rable reduction in the overall communicative value of the translation in relation to the original SL text. Thus the attempt to produce a sonorous and eloquent "poetic" rendering of at least certain portions of the Scriptures those of undeniable literary quality to begin with - would seem to be justified, as long as there is a needy receptor constituency that is either calling for such a translation, or who audience research suggests would presumably benefit from one. Translators would endeavour to do this, however, not by means of a mechanical feature-for-feature, passage-by-passage method, but rather in terms of larger chunks of text, in accordance with the dominant communicative functions that happen to be operative over those particular stretches of discourse.

\subsection{The oral-aural factor and an "oratorical" version}

What exactly is a "literary" translation then, and how does it differ from some of those mentioned earlier, the "common language" (CL) and "popular language" (PL) versions in particular (cf. Fig. 4)? Wonderly broadly defines such "literary" translations as follows:

These are fully contemporary, are oriented to the general public (not just the Christian in-group), and vary from regular to formal in their [sociolinguistic] functional variety. They make free use of all the resources of the language at all levels which are considered acceptable for published materials, and are thereby not intended to be fully accessible to the uneducated reader (1968:30).

Obviously a literary version as defined above can be produced only in a linguistic community that possesses a relatively long tradition of written literature. Its envisioned constituency, or target group, would be people who are comparatively well-educated, widely-read, and who enjoy the challenge of wrestling with the full range of lexical, grammatical, stylistic, and rhetorical usage in the particular language and society concerned. ${ }^{26}$

Does anything correspond to a "literary text" in the case of a language group that does not have such a long or strong tradition of literature and

It is imperative, therefore, that literary translators take the subtle but pervasive influence of verbal impact and appeal as well as personal emotions and attitudes, most seriously in their task of text-conceptual transformation.

26 A "literary" translation is not necessarily the same as a "liturgical" version, although the two types are sometimes confused. A liturgical Bible is often quite traditional in wording (closely following the SL text), hence not literary at all according to natural TL verbal norms and idioms - although it may regarded as such due to long usage and "official" promotion by the user churches. 
whose members communicate predominantly by oral-aural means? ${ }^{27}$ This situation would characterise most societies in Bantu Africa as well as in many other regions of the world. In such cases, the closest equivalent might be termed an oratorical text - that is, verbally distinctive oral discourse that accesses the complete inventory of genres and styles in the spoken language to convey a message that is widely regarded by listeners as being impressive, persuasive, and beautiful. Such semi-formal, oral-rhetorical usage would exclude youthful jargon and foreign-based colloquialisms (e.g. English borrowings and calques) on the one hand and widely unintelligible archaisms or specialist in-group technical argot on the other (e.g. vocabulary pertaining to specific occupations or activities like hunting, fishing, house-building, herbalistic medicine, or traditional initiation ceremonies).

Nowadays, such an "oratorical" style is manifested in the main by popular singers, public speakers, and radio broadcasters, including skilful oral performers of ancient verbal art forms as well as Christian evangelists and revivalists. ${ }^{28}$ Thus many recognised models of excellent oratory style do exist; however, they must be carefully collected (often by audio recording, hence requiring transcription), analysed, and printed (or broadcast) in order for standards of popular and specialist assessment to develop to the point where they may be effectively applied in written literature. Of course, the medium of print itself requires certain compositional modifications to be made during the transposition to a published text, for example, less overt repetition, a more explicit expression of content (to counteract the lack of an extralinguistic situational context), compensation for suprasegmental, intonational, and elocutionary (phonological) significance (e.g. the use of commas to represent dramatic pauses), more precise conjunctive and transitional devices ("function words"), and a lower incidence of informal or colloquial diction.

The use of these oral models and stylistic techniques is particularly appropriate for translations of the Bible, which are much more frequently ac-

27 In the keynote passage that begins this essay (Ps. 45:2), the terms "speaking" and לִשוֹי "my tongue" highlight the crucial oral-aural aspect of the biblical message that we both read (in the original) and translate.

28 I present the results of an extensive study of an outstanding representative of the last mentioned group in Wendland (2000). These texts may provide good models that can serve in the development of an "oratorical style" of rendering the paraenetic texts of the Bible, such as we have in the prophetic and epistolary literature. 
cessed by the ear than the eye. ${ }^{29}$ Furthermore, recent research has tended to confirm the hypothesis that the various documents of the Scriptures were in large measure composed aloud and/or were written down with an oralaural transmission and reception of their message in mind (cf. Achtemeier 1990; Fox 1995: Preface; Alter 1996:xx), ${ }^{30}$ perhaps with the aim of rendering the texts to "sound like orally composed speeches" (i.e. in the case of the Hebrew prophets; Floyd 2000:138). Consequently,

[s]ince the acts of both writing and reading were normally accompanied by vocalization, the structure [and style] of [the] text was marked by aural rather than visual indicators (Davis 1999:11). ${ }^{31}$

This fact (assumed here to be true) has important implications for both the analysis as well as the ongoing transmission of the biblical text via translation. For one thing, such prominent aural sonic, stylistic, and structural "indicators" - the "rhythmic envelope" of discourse, including its audio-

29 The preface to the Contemporary English Version states this point well:

Languages are spoken before they are written. And far more communication is done through the spoken word than through the written word. In fact, more people hear the Bible than read it for themselves. Traditional translations of the Bible count on the reader's ability to understand a written text. But the Contemporary English Version differs from all other English Bibles - past and present - in that it takes into consideration the needs of the hearer, as well as those of the reader, who may not be familiar with traditional biblical language (American Bible Society, 1995; original italics).

This final claim concerning its uniqueness may be somewhat of an overstatement, but for our purposes the point is simply this: an oratorical version is meant primarily to be orally read, to be clearly understood aurally, and to make its artistic-emotive impression upon an audience through the message as it is being heard by them.

30 One reason for such a need is simply the relatively low literacy levels (with respect to longer "literary" texts) among the general population in biblical times (Ben Zvi 2000:5; cf. p. 17, footnote 52).

31 Similarly, concerning the Old Testament, Dorsey writes:

[A]ncient texts were written primarily to be heard, not seen. Texts were normally intended to be read aloud ... To study structure in the Hebrew Bible, then, requires paying serious attention to verbal structure indicators ... (1999:16).

Such "aural indicators" would include features such as: rhythmic lineation, phonic accentuation, verbal patterning, prominent discourse demarcative devices, lexical recursion, direct speech, graphic diction, oral emphasisers, and vivid imagery (to promote topical-thematic recall). 
"punctuation" devices - need to be reproduced by means of functionally equivalent methods in a translation, including the skilful use of typographic formatting techniques (Wendland 1994). This "oral-elocutionary" dimension of meaning, "the spokenness of the Bible" (Fox 1995:xv), is a particularly important consideration in the case of any specifically "oratorical" version, which is primarily meant to be heard rather than read.

However, a possible objection to an "oratorical", or indeed a "literary", translation needs to be considered. This concerns a stylistic comparison and evaluation with respect to the original texts of Scripture. Thus, one might question whether an artistic-rhetorical manner of composition constitutes a distortion of - in this case, an intentional "improvement" upon — the supposed vernacular "common-language," or koine, style of the New Testament documents. ${ }^{32}$ Are we perhaps in danger here of over-translation? In other words, to what extent are the biblical books themselves "literary" (or "oratorical") in nature - that is, of recognisable, demonstrable excellence with respect to their thematic, structural, and affective qualities? Furthermore, how would the results of such a compositional assessment if carried out today compare with those derived from the original setting? Obviously, no direct comparison of this kind can be made, and to provide a credible and convincing answer to such questions would require a much more extensive study than I have space for here (cf. Sections $2.3,4.1){ }^{33}$ Such potentially controversial issues also need to be considered in relation to a specific translation text, audience, intended occasion, and setting of use. The day of the "one-size-fits-all" type of version would appear to be long past.

\subsection{Primary characteristics of a literary (oratorical) version (LT)}

My major premise is that a well-prepared, fully functional-equivalent translation of the Bible will normally turn out to be a recognised literary text in the target language - manifested on all linguistic levels, from indigenous text genres to significant local patterns of sound. In short, an LT might be characterised as being a stylistically "extended" and/or a rhetorically "en-

32 A stylistic assessment of the of the Hebrew Scriptures is of course more difficult to make due to the limited corpus of texts, religious or secular, on the basis of which an adequate analytical comparison may be made (even in cognate literatures). However, the diversity and abundance of "universal" Semitic literary features that are manifested in many Old Testament passages greatly reduces the doubt concerning this issue.

33 The various essays in Zvi and Floyd (2000) strongly presuppose the literary character of the prophetic corpus. 
hanced" popular-language version (cf. Wonderly 1968:3). Therefore, if the original has been determined to be literature (and different degrees of artistic and oratorical distinction may be recognised with respect to the various books), then its corresponding interlingual reproduction should be similarly regarded, in accordance with recognised standards of verbal excellence in the vernacular. A great deal of formal correspondence with the original text will inevitably be lost in this effort to gain "pragmatic resemblance" - "a [perceptible] similarity of communicative functions" (De Beaugrande 1968:94) — with respect to individual passages as well as the translation as a whole. But it is hoped that a high degree of situational and personal "relevance" for the intended audience will be gained as a result of this disciplined exercise in artful text reconstruction. ${ }^{34}$

The approach to translation highlighted in this article is one that might be technically termed "literary functional equivalence" (cf. Wendland 2002). "Literary" may sound like a redundant qualifier of "functional equivalence", especially with regard to Bible translation, ${ }^{35}$ but its inclusion here enables one to distinguish the present, more focused perspective from earlier descriptions of this notion. In the latter, the literary character of the Biblical texts was downplayed and attention was concentrated on the lower levels of textual composition. "Equivalence" too is a problematic term; however, its continued use in current translation studies, the lack of a suitable or widely agreed upon substitute, and its indication to Bible translators of the importance of accurately representing the source text, may be reason enough to justify its retention. ${ }^{36}$ The expression "literary functional

34 As already noted, "relevance" refers to a bi-directional (SL $\Longleftrightarrow \mathrm{TL}$ ), situationally determined appropriateness with respect to efficiency (the least conceptual "processing" effort) on the one hand and effectiveness (the greatest cognitive gain or communicative impact) on the other.

35 According to the earlier definition of literary translation (Fig. 3), the approach of "functional equivalence" specifies the qualifier "literary" - both of which together refer to a specific type of translation, namely, one that happens to be especially "relevant" to a particular TL constituency (as delineated in its governing project skopos).

36 It is becoming increasingly apparent that the effort to achieve total "functional equivalence" with regard to the source language and target language texts in their entirety is an unrealistic goal to aim for in Bible translation, where two very different languages, cultures, environments, and communal as well as individual cognitive states are involved. Thus an "equivalent" kind of communication in terms of complete equality, i.e. with regard to "value" (Reiss 2000:3; Hermans 1999:54), is impossible to accomplish, even in cases where a well- 
equivalence" indicates that this aspect of a current UBS approach is a development (and corrective) of — rather than a radical break from - earlier statements on Bible translation developed primarily through the influence of Eugene Nida. Such a method offers a great potential for creatively, yet also faithfully representing selected biblical texts for a more sophisticated, aurally-appreciative audience. However, the degree to which translators can actually work towards this communicative goal may be considerably limited by the sociocultural and organisational (ecclesiastical) frames within which they work, and/or by their own lack of training and qualifications.

The main operational characteristics of a literary functional-equivalence approach may be summarised as follows:

- A discourse-centered, genre-based perspective, viewing the parts of a text to be analysed and translated in terms of the linguistic and literary whole, and the whole correspondingly in terms of its constituent compositional parts, with respect to the creative genius of both the SL and also the TL in general comparative relief;

- A prominent pragmatic-functional component which assumes that the producer of a text, whether the original author or a translator, arranges its form and content to convey particular communicative goals (text/ speech-acts), at selected linguistic levels, with varying degrees of specificity, and within possibly diverse frames of sociocultural and situational reference;

- A concern for how the overall contextual framework (i.e. the intra-, interand extratextual setting) of a given passage might have influenced early interpretations of the original text and also how the contemporary situational setting (including the relevant social, literary, and ecclesiastical norms) of the translated passage will be likely to affect the intended audience's interpretation (to be subsequently tested for verification);

- A focus upon the interrelated artistic and rhetorical dimensions of discourse, which involve the relative appeal (aesthetic attraction) and impact (persuasive power) of the biblical message as it was produced

prepared meaning-based translation is accompanied by a host of explanatory or descriptive footnotes and other extratextual aids. In short, the respective communication frameworks are simply too disparate for there to be total equivalence. The best that translators can hope to attain then is varying degrees of "parity," or approximation - that is, a relative equivalence in certain pre-determined respects pertaining to form, content, and/or function in accordance with the project skopos. 
(conceived, composed, conveyed) and processed (hearing, reading) during the original act of verbal communication (a hypothetical construct);

- A special interest also in the key oral-aural dimension of the biblical message, with reference to the process of initial text transmission (including its creation and reception) as well as its transformation (including recomposition and reformatting), within the communicative framework of a different language, translation tradition, set of literary conventions, sociocultural (including religious) setting, media network, and interpersonal situation;

- A practical heuristic that considers the principal stylistic qualities of a literary version in terms of three integrated sets of general features: unity, diversity, and rhetoricity; structure, patterning, and foregrounding; imagery, phonicity, and dramatics (cf. Wendland 2002). ${ }^{37}$ These discourse characteristics are complementary and closely interconnected, even overlapping on occasion with respect to their manifestation in the diverse texts of the Bible; they must therefore be analysed and applied accordingly in the holistic, synthetic act of translation.

The extent to which the preceding points may be actually applied in a translation depends on a wide range of variables. Not the least of these are the resources allocated to a project, including the qualifications of the translators and support for their ongoing training as well as for a periodic assessment and possible revision of the text. Another key factor is the degree to which a new translation is expected to look like other ones, either in the same language or some lingua franca. This desire for a perceptible similarity to the known often entails limiting functional equivalence to the paragraph level, and reproducing traditional format items such as numbers prominently marking every verse. To my knowledge, there is no published version in any language that could be said to consistently represent a full literary functional-equivalence approach to translation (in the "technical" sense; cf. Sections 2.2, 3.2). However, it is hoped that the present discussion will encourage some serious thinking or even a bit of experimentation along these lines.

37 The first set includes factors that are most general and foundational in nature; they are thus presupposed to varying degrees by all of the others. The second set pertains largely to the macrostructure of a text, while the third is associated more with the microstructure of literary discourse. 
This is not to suggest, however, that a complete "literary" version is the only valid option. It has been emphasised that there is a broad continuum of translation types or styles to choose from, ranging from the comparatively literal to the qualitatively more idiomatic and dynamic in nature. A literary functional-equivalent approach may thus be applied in a relatively fuller or a more limited way during a given translation program. Furthermore, it is ideally accompanied by creative text-formatting techniques and a generous array of supplementary descriptive and explanatory notes or introductions, as in a study Bible format. ${ }^{38}$ There are also different sizes of text that may be chosen for this compositional exercise, from an individual selection (e.g. the book of Psalms) or pericope (e.g. 1 Corinthians 13) to the Bible as a whole.

As already noted, the portion to be translated and the most fitting methodological approach will depend on many local situational influences, including the obvious human factor as well as the less apparent consideration of choosing a suitable medium of transmission. Thus, before any translation project is undertaken, the manifold frame of the overall communication context will need to be thoroughly researched and an appropriate $s k o-$ pos formulated with regard to guiding principles and practical procedures - all in consultation with a broad spectrum of representatives from the target language community. The principal appeal, or argument, of this article has been that, when and where the circumstances allow and are supported by the intended user group, a greater measure of artistic functional equivalence, or literariness (i.e. Scripture rendered as recognised literature), should be considered as a possible goal to which capable and creative translators might aspire.

\section{CONCLUSION: SOME IMPLICATIONS OF ADOPTING A LITERARY APPROACH}

I will conclude this preliminary study of the possibilities that are presented by a literary rendition of the Scriptures by summarising some major implications in terms of its overall "relevance" to a given TL community:

[W] henever a person engages in ostensive communication, she creates the tacit presumption that what she has to communicate will

38 A format that includes such features as a single column of print, selective indentation, and various type styles could be used to display major parallels and other patterns that are found in the original discourse structure. Additional notes would be required to explain the nature and significance of such devices as they appear in the translated text. 
be optimally relevant to the audience: that it will yield adequate contextual effects, without requiring unnecessary processing effort (Gutt 1992:25).

How do these relevance principles, expanded in reference now to a larger complex of auxiliary as well as direct communicational activities, apply in relation to a specific translation project as a total enterprise? In other words, what sort of assumptions does (or should) an ostensive act of literary communication stimulate within the intended audience?

\subsection{Cost}

There is no denying the fact that a considerable "cost" in terms of effort and expense is needed to produce an acceptable literary version, that is, compared with other types of rendering that would be much less rigorous in their demands upon the translation team. In fact, the requisite resources required at the very outset may be so overwhelming, or so completely lacking within the TL community, that such a possibility, even a mere vision, cannot even be considered. It is necessary therefore for the project's planning committee to "first sit down and estimate the cost" (Lk. 14:28). We might begin with the sine qua non - namely, those communication and media experts who will comprise the staff of the translation team. Are all sponsoring churches thoroughly committed to second and support (financially, educationally, spiritually) persons of such high intellectual and artistic calibre to cope with a challenge of this magnitude?

Second, are people ready to pay what will in all likelihood amount to be the higher "price" of conceptually processing and interacting with a literary rendition if and when it becomes available - for example, a text that has been composed entirely in some popular TL poetic genre? Such a version will not be expressed either in the familiar (but often misunderstood) words of a traditional, more literal Bible or using the simplified, perhaps restricted linguistic forms of a "common-language" rendering. It will certainly require considerable effort for the translators, first of all, to verbalise an artistically poetic, yet also exegetically accurate text - then for the intended audience to sufficiently understand, appreciate, and apply it (at least to start with, while they are still getting used to its novel stylistic forms and more elaborate discourse structures). Thus the management team may face a certain amount of general resistance and promotional difficulty when beginning their attempt to "sell" the constituency at large on the merits of such an unconventional translation. A great amount of proactive, but gentle education may be necessary to overcome the possible "alienation" that a 
literary version in the vernacular might cause among certain groups within the wider Christian community.

\subsection{Gain}

How do the preceding costs balance out when offset by the actual (not merely potential) benefits of a literary-oratorical translation? Of course, a practical assessment of this sort may take some time to complete, as people gradually grow in their understanding of the positive features of an artistically-composed poetic (narrative, expository, paraenetic, etc.) text and how/where to make use of such a version of the Scriptures to increase the various personal and communal "contextual effects" that may potentially be derived from it (Gutt 1992:22-23). As noted earlier, a fully literary translation (LT) may not be acceptable, at least initially, for general liturgical purposes in a public worship service. However, it will certainly possess some significant communication possibilities for particular audience subgroups in specific situations or special (e.g. oral-aural) settings - that is, in accordance with the guiding skopos statement that was prepared as an essential part of the initial project brief.

For example, an LT may be very appropriate for use as part of a varied strategy of youth ministry or as an unconventional outreach tool designed to appeal to groups that normally tend to be resistant or not attracted to the Christian message, e.g. members of local "ethnic-pride" groups and anti-Western traditionalists or popular entertainers, artists, and public performers of all types - painters, sculptors, musicians, dramatic players, actors, TV personalities, well-known sportsmen and women. An LT might turn out to be especially attractive to or welcomed by those who live in completely different socioeconomic circumstances: street kids, the destitute, members of the drug culture, and other outcasts (i.e. contemporary African "publicans and sinners"). An LT may also be found to be highly suitable for certain non-print media productions (e.g. audio-cassette or CD, especially when accompanied by compatible background music or actually composed in a popular song style) and in mass media broadcasting efforts (audience-specific radio programmes in particular).

There is one special, personal gain in communicative effects that is more or less certain to be realised. This has to do with the increased emotive and aesthetic benefit that will accrue to all those who regularly make use of an LT, especially in close conjunction with a more traditional literal and/or liturgical version. A poetic rendition, for example, could serve as a valuable devotional resource and a helpful means of expanding or enhancing a believer's understanding of and appreciation for the great artistic, 
rhetorical, emotional, ethical, and theological riches to be mined from the ancient texts of the Word of God — as genuine, contemporary literature in the TL - and surprisingly perhaps, from many more passages than s/he might have formerly thought possible.

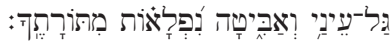

Open my eyes, so that I may see the wonderful truths in your law.

(Ps. 119:18 - GNB)

\section{BIBLIOGRAPHY}

\section{Alter R}

1981. The art of biblical narrative. New York: Basic Books.

1996. Genesis: translation and commentary. New York: W.W. Norton.

\section{ACHTEMEIER P J}

1990. Omne verbum sonat: the New Testament and the oral environment of late Western antiquity. Journal of Biblical Literature 109/1:3-27.

\section{BAILEY J L \& VAN DER BROEK L}

1992. Literary forms in the New Testament: A handbook. Louisville: Westminster/ John Knox.

BARR J

1963. The Bible in the modern world. London: S.C.M.

DE BEAUgRANDE R 1968. Factors in a theory of poetic translating. Assen: Van Gorcum.

\section{Ben Zvi E}

2000. Introduction: writings, speeches, and the prophetic books - setting an agenda. In: Ben Zvi and Floyd (eds.) 2000:1-29.

\section{Ben Zvi E \& FloYd M H}

2000. Writings and speech in Israelite and ancient Near Eastern prophecy. Atlanta: Society of Biblical Literature.

\section{BERLIN A}

1985. The dynamics of biblical parallelism. Bloomington: Indiana University Press.

\section{BRECK J}

1994. The shape of Biblical language: chiasmus in the Scriptures and beyond. Crestwood: St. Vladimir's Seminary Press. 


\section{Chesterman A}

1997. Memes of translation: The spread of ideas in translation theory. Amsterdam \& Philadelphia: John Benjamins.

\section{Davis C W}

1999. Oral biblical criticism: The influence of the principles of orality on the literary structure of Paul's Epistle to the Philippians. Sheffield: Sheffield Academic Press.

De WAard J \& NIDA E A

1986. From one language to another: functional equivalence in Bible translating. Nashville: Thomas Nelson.

\section{DORSEY D}

1999. The literary structure of the Old Testament. Grand Rapids: Baker Books.

\section{FAWCETT P}

1997. Translation and language: linguistic theories explained. Manchester: St. Jerome.

\section{FLOYD M H}

2000. "Write the revelation!" (Hab 2:2): Re-imagining the cultural history of prophecy. In: Ben Zvi and Floyd (eds.) 2000:103-143.

\section{Fox E}

1995. The five books of Moses: a new translation with introductions, commentary, and notes. New York: Schocken Books.

\section{GREEN H B}

2001. Matthew, poet of the Beatitudes. Sheffield: Sheffield Academic Press.

Guralnik D B (ed.)

1988. Webster's new world dictionary [Third College Edition]. New York: Webster's New World.

\section{GUTT E-A}

1991. Translation and relevance: cognition and context. Oxford: Blackwell.

1992. Relevance theory: a guide to successful communication in translation. Dallas: Summer Institute of Linguistics.

HARVEY J D

1998. Listening to the text: oral patterning in Paul's letters. Grand Rapids: Baker.

\section{HATIM B \& MASON I}

1990. Discourse and the translator. London: Longman.

1997. The translator as communicator. London: Routledge.

\section{HERMANS T}

1999. Translation in systems: descriptive and system-oriented approaches explained. Manchester: St. Jerome. 
KATAN D

1999. Translating cultures: an introduction for translators, interpreters and mediators. Manchester: St. Jerome.

Lundin R, WALhOUT C \& Thiselton A (eds.) 1999. The promise of hermeneutics. Grand Rapids: Eerdmans.

\section{NidA E A \& TABER C R}

1969. The theory and practice of translation. Leiden: Brill.

\section{Nord C}

1997. Translation as a purposeful activity: functionalist approaches explained. Manchester: St. Jerome.

\section{NORTON D} 2000. A bistory of the Bible as literature. Cambridge: Cambridge University Press.

POMORSKA K \& RUDY S (eds.)

1985. Roman Jakobson: verbal art, verbal sign, verbal time. Minneapolis: University of Minnesota Press.

\section{PILKINGTON A} 2000. Poetic effects. Amsterdam \& Philadelphia: John Benjamins.

\section{ReIsS K [RHODES E trans.]}

2000. Translation criticism: the potentials E limitations. Manchester: St. Jerome.

\section{SCHOEKEL L A}

1988. A manual of Hebrew poetics. Rome: Editrice Pontifico Instituto Biblico.

\section{SOUKHANOV A H (ed.)}

1996. The American heritage dictionary of the English language. [Third Edition.] Boston \& New York: Houton Mifflin Co.

\section{STERK J}

2001. Translation and media: how different can we be and still be equivalent? Paper presented at the conference on similarity and translation (New York, May 31-June 1), 1-16.

\section{TATE W R}

1991. Biblical interpretation: an integrated approach. Peabody: Hendrickson.

\section{Thiselton A C}

1999. Communicative action and promise in hermeneutics. In: Lundin et al. (eds.) 1999:133-239.

\section{TOURY G}

1995. Descriptive translation studies and beyond. Philadelphia: John Benjamins.

\section{VANHOOZER K}

1998. Is there a meaning in this text? The Bible, the reader, and the morality of literary knowledge. Grand Rapids: Zondervan. 


\section{WENDLAND E R}

1993. Comparative discourse analysis and the translation of Psalm 22 in Chichewa, a Bantu language of south-central Africa. Lewiston: Edwin Mellen Press.

1994. Oral-aural dynamics of the Word: with special reference to John 17. Notes on Translation 8/1:19-43.

2000. Preaching that grabs the heart: a rhetorical-stylistic study of the Chichewa revival sermons of Shadrack Wame. (Kachere Monograph No. 11.) Blantrye, Malawi: CLAIM.

2002. A literary approach to biblical text analysis and translation. In: Wilt (ed.):Ch. 6.

\section{WESTERMANN C}

1966. Basic forms of prophetic speech. Philadelphia: Westminster Press.

WILT T (ed.)

2002. Bible Translation: frames of reference. Manchester: St. Jerome.

WONDERLY WM L

1968. Bible translations for popular use. New York: United Bible Societies.

Keywords

Bible translation

Literary translation

Genre

Poetic quality

Translation types 